\title{
A ruling supreme?
}

\author{
Jim Simpson LLM ${ }^{1}$, Paul Adams MD² (Editor-in-Chief)
}

$\mathrm{J}$ im Simpson has been General Counsel of the Ontario Medical Association for the past 10 years. Before that, he practiced civil litigation in Toronto, Ontario.

PA: Can you summarize briefly the recent ruling in the Supreme Court?

JS: The legal precedent set by the Supreme Court's decision is actually quite narrow. The Court ruled, by a 4:3 majority, that s. 15 of the Health Insurance Act (Quebec) and s. 11 of the Hospital Insurance Act (Quebec), which prohibit private health insurance for physician and hospital services, violated s. 1 of the Quebec Charter of Human Rights and Freedoms, which states, "Every human being has a right to life, and to personal security, inviolability and freedom".

Hence, in Quebec, it is now legal for private insurance companies to sell insurance for physician and hospital services. Since this article was originally written, the Supreme Court of Canada has granted a one-year stay on the effect of its decision.

PA: Does this mean that Canadians can start buying private health insurance for services covered by their provincial health plans?

JS: No. Strictly speaking, this decision estab-

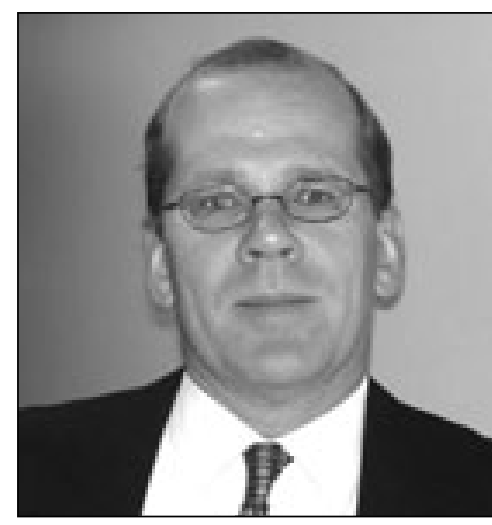

Jim Simpson has been General Counsel of the Ontario Medical Association for the past 10 years. Before that, he practiced civil litigation in Toronto, Ontario lished no precedent outside Quebec. The

Supreme Court was split 3:3 on whether this prohibition also violated s. 7 of the Canadian Charter of Rights and Freedoms which states, "7. Everyone has the right to life, liberty and security of the person and the right not to be deprived thereof except in accordance with the principles of fundamental justice".

Justice Deschamps did not consider the application of the Canadian Charter in her decision. Hence, we do not know whether the prohibitions on private insurance in Ontario, Manitoba, Alberta, British Columbia and Prince Edward Island are also invalid. The only way we will know whether these prohibitions are valid is if the issue is relitigated and a decision is made under the Canadian Charter. It is difficult to speculate what the outcome might be if the Supreme Court rehears this issue. If that happens, it is almost certain that the full court of nine judges would hear the appeal.

PA: Does this mean that Canadian doctors can start charging patients for services? If you do charge patients, are you violating the Canada Health Act, and has this changed now with this new ruling?

JS: Actually, in seven provinces, physicians can currently set their own fees. Only Ontario, Nova Scotia and Manitoba prohibit nonparticipating physicians from charging their patients more than what physicians receive from the public plan. This decision does not alter the situation in these three provinces.

What is widely misunderstood about this decision, is that this is not the effect of the Canada Health Act. The Canada Health Act does not prohibit private health care in Canada. The Canada Health Act merely requires provinces, as a condition of receiving full federal financial contributions for health care, to establish a health care insurance plan that satisfies the five criteria listed in the Act.

The prohibitions on private health insurance and on charging fees outside the provincial health care plan that are higher than those paid under the plan have been created by the provinces. That is why there is the variability between the provincial plans noted above. The provinces have exceeded the requirements of the Canada Health Act and created their own restrictions on the delivery of medical care.

PA: Many of our readers will be contemplating starting up ambulatory endoscopy clinics to do screening colonoscopy and other procedures. Is there a difference between charging for screening procedures and medically indicated procedures?

JS: Ontario, Nova Scotia and Manitoba prohibit nonparticipating physicians from charging their patients more for 'insured services' than what physicians receive from the public plan. This prohibition has made many private clinics unviable. Generally speaking, an insured service is a medically necessary service listed in the province's Schedule of Benefits that is rendered by a physician in the province to a person who has been resident in the province for more than three months. The only way around the payment prohibition is to provide services that are not insured services. Hence, a private screening clinic that performs services that are not medically indicated or necessary, does not provide an insured service and hence can set fees greater than those paid by the plan in the province.

${ }^{1}$ Legal Department, Ontario Medical Association, Toronto; ${ }^{2}$ London Health Sciences Centre, London, Ontario

Correspondence: Mr Jim Simpson, 525 University Avenue, Suite 300, Toronto, Ontario M5G 2K7. Telephone 416-340-2940,

fax 416-340-2946, e-mail Jim_Simpson@OMA.org

Received for publication August 2, 2005. Accepted August 2, 2005 
This has created the perverse situation that where services are not medically necessary, they receive more prompt attention than services that are medically necessary. No rational health care system can operate on such an absurd basis.

PA: What do you see as the sequelae of this ruling?

JS: The importance of this ruling is that it clearly establishes that if a plaintiff can establish that long waiting lists exist for a certain procedure, and that such delays threaten patients' lives, increase the risk that their injuries will become irreparable by surgery, unnecessarily prolonged pain, diminish the enjoyment or quality of life or cause psychological and emotional stress, the court will conclude that the patient's right to "life or personal security" has been infringed. None of the 11 judges who heard this case over the five years it spent in the court system had difficulty with this principle.

The difficult issue for all three courts was whether this infringement was necessary to preserve the public health care system. In most provinces, when public health insurance was first introduced, private insurance/health care was not prohibited. However, at that time, most people paid for public insurance themselves. Provinces quickly discovered, or at least took the position, that their public insurance schemes were quickly becoming uncompetitive with the private schemes as they accepted all patients regardless of health status. Hence, provinces such as Ontario banned private insurance in 1969, three years after the introduction of public health insurance.

The belief that it is necessary to prohibit private insurance for public insurance to remain viable has lasted until present and was evident in Quebec's submissions to the Supreme Court. However, since that time, Quebec's insurance scheme has evolved from one where an individual elects to participate in the public system and make payment to it to a mandatory system financed by the general tax revenue system. The 4:3 majority of the Supreme Court held that there was no evidence whatsoever that a ban on private insurance continued to be necessary for a public scheme to operate.

This decision represents the first rational analysis of the public/private health system debate since Senator Kirby's report. The minority of the Supreme Court took the position that it was not the role of the courts to settle such a public policy debate. Fortunately, the majority held that the court had a duty to review the situation as the rights of Quebecers were being violated by the Quebec government.

This decision will force governments in the future to adduce valid evidence to substantiate the legitimacy of their policy considerations to justify further violations of Canadian's rights by their governments.

Canadian provinces are the only jurisdiction in the Organisation for Economic Co-operation and Development that prohibit, in varying degrees, private health insurance/private clinics. Hopefully, the parallel systems considered by the Supreme Court from Sweden, Germany, the United Kingdom, France, Switzerland, Australia and New Zealand can now be considered in seeking an appropriate public/private mixture for Canada. 


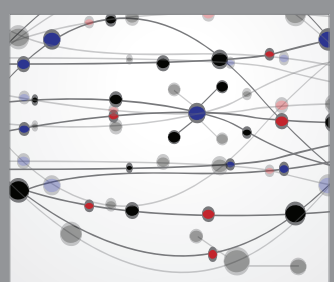

The Scientific World Journal
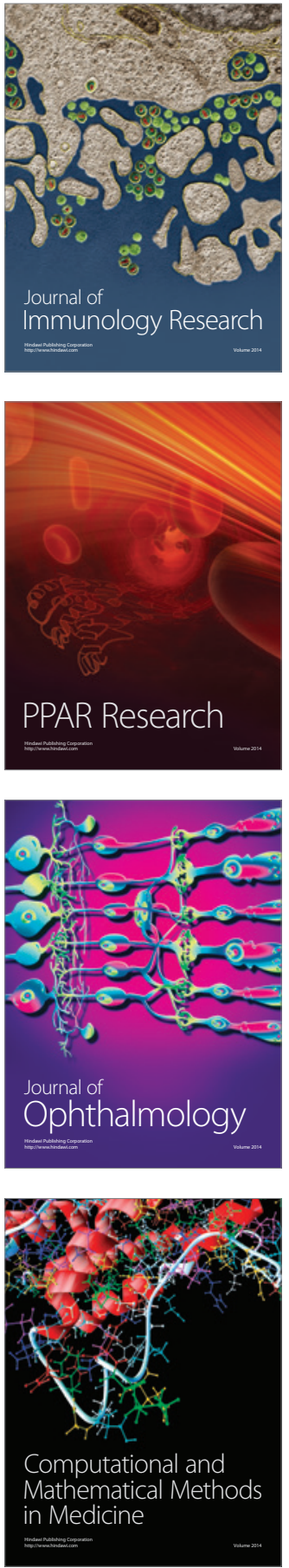

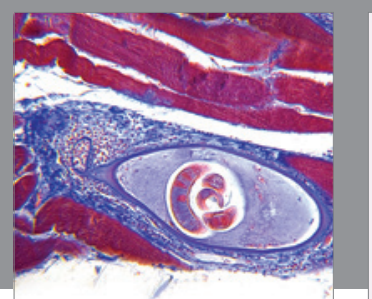

Gastroenterology Research and Practice

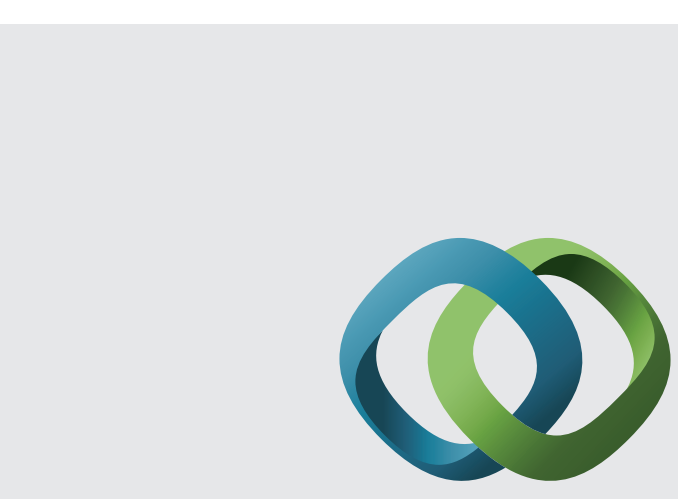

\section{Hindawi}

Submit your manuscripts at

http://www.hindawi.com
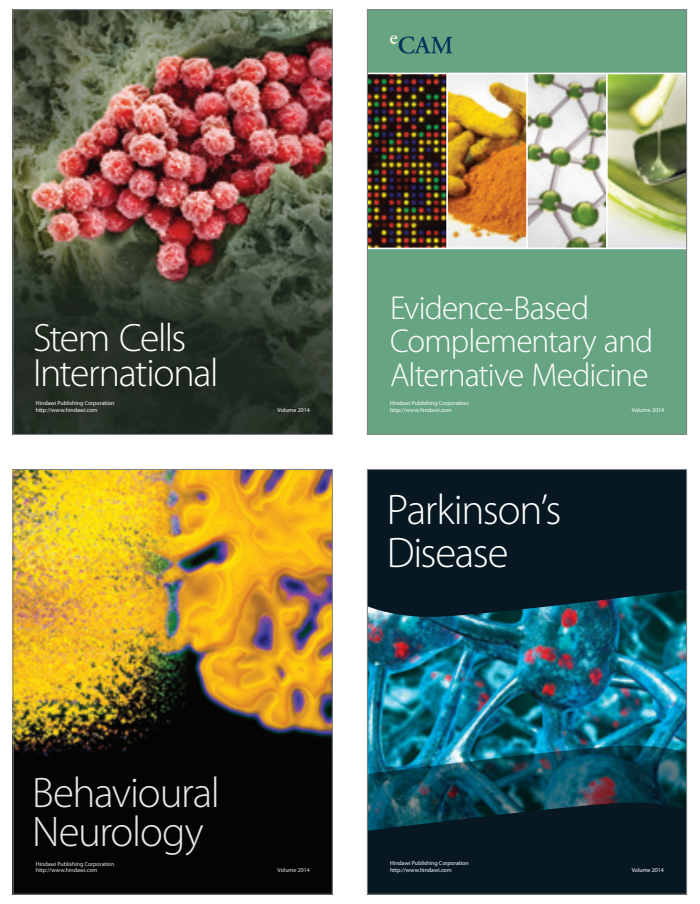
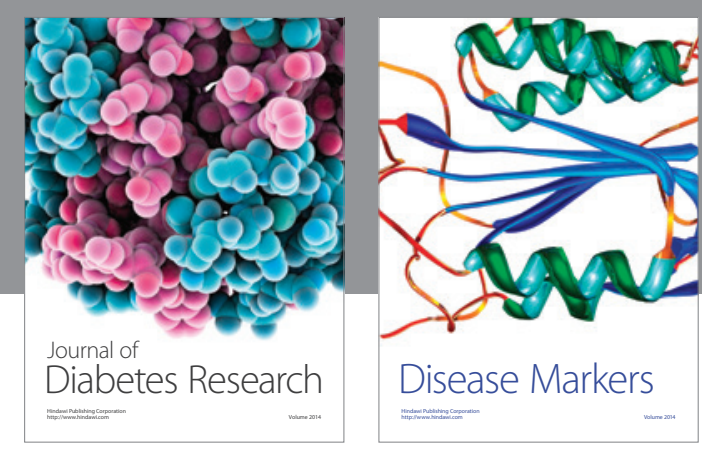

Disease Markers
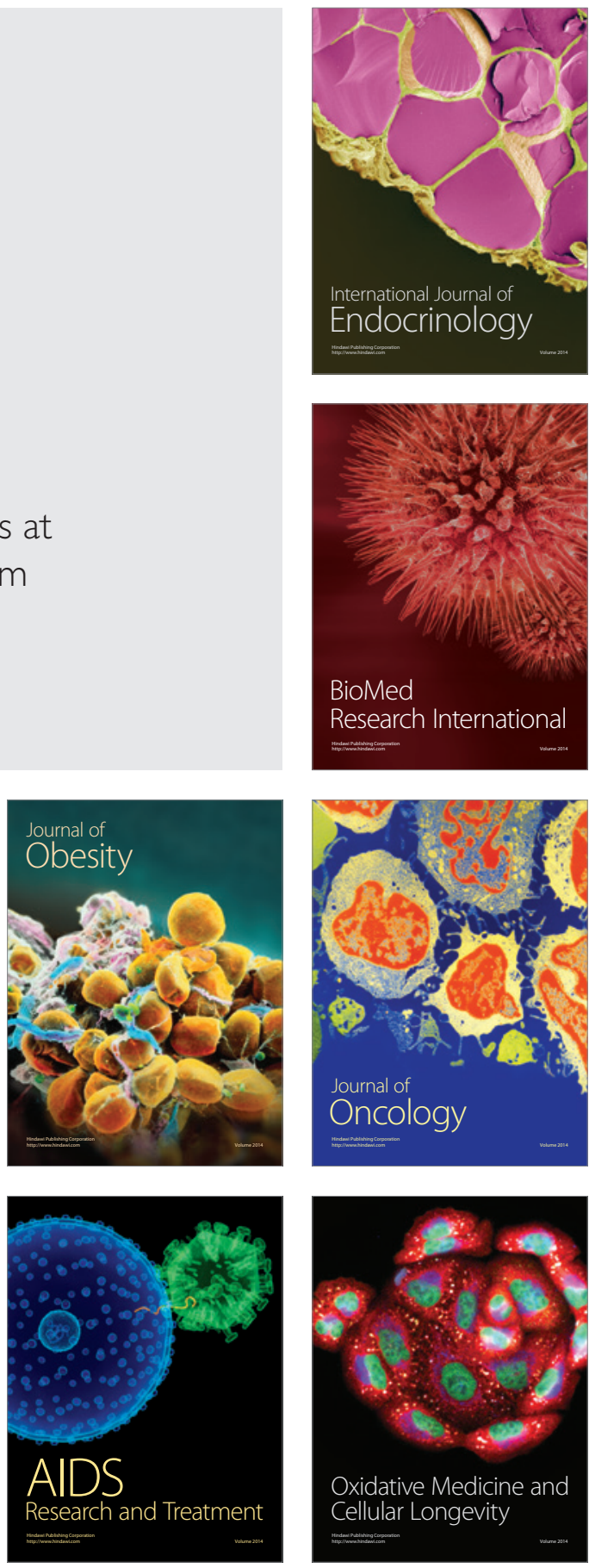